\title{
The Effect of Inhibitor on the Corrosion of Aluminium in Acidic Solutions
}

\author{
Uma $K^{1,2 *}$, Rajapriya $V^{3}$, Rekha $S^{4}$ \\ ${ }^{1}$ Research \& Development Centre, Bharathiar University, Coimbatore \\ ${ }^{2,3}$ Department of Chemistry, Prathyusha Engineering College, Thiruvallur \\ ${ }^{4}$ Department of Chemistry, RMD Engineering College, Kavaraipettai, Chennai
}

Received: November 15, 2016; Accepted: November 30, 2016; Published: December 20, 2016

*Corresponding author: K Uma, M.Phil, Assistant Professor, Department of Chemistry, Prathyusha Engineering College, Thiruvallur, Tel: +91-984-0271340; E-mail: umachem74@gmail.com

\begin{abstract}
Many industries are replacing highly corrosive sulphuric acid fluoroboric acid and fluorosilicic acid by MSA as environmentally superior alternatives to the currently used systems. In present study the rate of corrosion on aluminium in Sulphuric acid and Methane sulphonic acid was comparatively studied. The results show that methane sulphonic acid is far less corrosive than sulphuric acid. The inhibition of aluminium in methane sulphonic acid in the presence of thiourea has also been evaluated by weight loss techniques and temperature effects. Values of inhibition efficiency obtained are dependent upon the concentration of inhibitor and temperature. The experimental data are complied with Temkins Adsorption isotherm and SEM studies are carried out on the corroded surface.
\end{abstract}

Keywords: Corrosion; Inhibition Efficiency; Aluminium; Weight Loss; Methane Sulphonic Acid;

\section{Introduction}

The corrosion behaviour of amorphous metallic alloys is important property to understand their chemical stability against corrosive environment. Corrosion has the tendency to degrade the useful properties of materials and structure including strength, appearance and permeability to liquids and gases. Corrosion is also defined as the deterioration of a material, usually a metal, because of a reaction with its environment. It depends on a natural phenomenon that occurs over time, an electrochemical reaction (on metals) and also happens at different rates with different metals and in different environments. Corrosion control can be achieved by the use of inhibitors [1]. This phenomenon necessitates the continuous search for better corrosion inhibitors due to vast differences in the media encountered in industry which remains a focal point in corrosion control as inhibitors slow down the corrosion process on metals. A number of organic compounds [2-10] are known to be applicable as corrosion inhibitors for aluminium in acidic environment. Usually, acid solutions are generally used for the removal of undesirable scale and rust in several industrial processes. Acids are widely used in the pickling process of metals. Most of the severe corrosion problems encountered involve the mineral acids or their derivatives. Use of inhibitors is one of the most practical methods for protection against corrosion especially in acid solution to prevent metal dissolution and acid consumption. [11]. When compared to other mineral acids, methane sulphonic acid is usually described as a "green acid" due to its environmental advantages $[12,13]$. Methane Sulphonic Acid is a colourless liquid with the chemical formula $\mathrm{CH}_{3} \mathrm{SO}_{3} \mathrm{H}$. MS A may be considered as intermediate compound between sulphuric acid and methyl sulfonyl methane, effectively replacing an $-\mathrm{OH}$ group with a $-\mathrm{CH}_{3}$ group at each step. MSA is a strong organic acid with pka=-1.9[14] with low tendency to oxidize organic compounds. MSA is far less corrosive and toxic than usual mineral acids employed industrial processes [15]. MSA is biodegradable within 28 days, only carbon- di- oxide and sulphates being formed [16] and it is recyclable up to $80 \%$. It is environmentally advantageous electrolyte. There is several manufacturing process. In the chloro oxidation process (the conventional one, developed by pennwalt corporation in 1967[17]), methane thiol is oxidized by chlorine to form methane sulphonyl chloride, which is then to be hydrolyzed to form MSA with $\mathrm{HCl}$.

$$
\mathrm{CH}_{3} \mathrm{SH}+3 \mathrm{Cl}_{2}+3 \mathrm{H}_{2} \mathrm{O} \rightarrow \mathrm{CH}_{3} \mathrm{SO}_{3} \mathrm{H}+6 \mathrm{HCL}
$$

Compounds typically contain nitrogen, oxygen or sulphur in a conjugated system and function via adsorption of the molecules on the metal surface creating a barrier to corrodent attack. The adsorption bond strength is dependent on the composition of the metal and corrodent inhibitor structure and concentration as well as temperature. Despite the broad spectrum of organic compounds, the choice of appropriate is restricted by several factors. Most of the acid inhibitors are organic compounds contain nitrogen [18-20], oxygen [21-24], phosphorous [25] and sulphur [26-27].

The purpose of the present work is to prove the corrosive nature of msa is far less than sulphuric acid and to study the inhibitive action of thiourea on aluminium in 1 M MSA using 
weight loss techniques and thermometric method. In addition adsorption isotherm will be investigated. Inhibited metallic surface are examined by using scanning electron microscope.

\section{Experimental Section}

\section{Specimen preparation}

Aluminium metal with purity $98.5 \%$ was used in the present study. Each sheet was $0.1 \mathrm{~cm}$ in thickness and was mechanically press cut into $5 \mathrm{~cm}$ X $2.5 \mathrm{~cm}$ coupons. Each specimens were ground manually under a stream of water starting with 400 grit sic paper and continued and with 800, 1000, 1200 grit papers. Between each paper change, the sample was rinsed with distilled water to remove the particles arising during grinding. Each sample was ground in one direction until all imperfections were removed and the surface was covered with a uniform pattern of scratches. The polishing procedures were repeated until to achieve a mirror finish. After polishing, the samples were degreased by washing with ethanol, dried in acetone and preserved in a desiccator. Described procedure was used for the preparation of samples for the electrochemical and immersion tests as well as for the surface analysis. All reagents used for the study were analar grade and double distilled water was used for their preparation.

\section{Preparation of different composition of MSA, Sulphuric acid and Inhibitor}

The solutions used were made of analar grade sulphuric acid and methane sulphonic acid. Appropriate concentrations of acids were prepared by using triple distilled water. The various concentration of $0.1 \mathrm{~N}, 0.5 \mathrm{~N}, 1.0 \mathrm{~N}, 1.5 \mathrm{~N}, 2.0 \mathrm{~N}$ was prepared for both sulphuric acid and MSA. Thio-urea provided by Merck was used as inhibitor. The concentration range of employed inhibitor was $100-400$ ppm in 1M MSA.

\section{Weight loss method}

Non-electrochemically, the rate of corrosion can be determined by conventional weight loss technique method. Using this technique, the loss of a metal due to corrosion is measured by exposing the metal specimen of known area to the corrosive environment for a particular period and finding the difference in weight before and after exposure. The cleaned and dried aluminium coupons were weighed and suspended with the aid of glass hook in a beaker contain $100 \mathrm{ml}$ of $1 \mathrm{M}$ MSA solution with and without different doses of thiourea concentration ranged from 100-400 ppm. The coupons were taken out of the test solution after 12 hours, washed in $70 \%$ nitric acid to remove the corrosive product using bristle brush, rinsed with distilled water, dried and reweighed. From the initial and final weight, the loss in weights was calculated. Corrosion rate and inhibition efficiencies were calculated by using the formula:

$$
\text { Corrosion rate } \rightarrow \frac{\text { Weight loss X } 100}{\text { Surface area (dm2) X Time (days) }}
$$

$$
\% \text { of Inhibition Efficiency } \rightarrow \frac{\mathrm{W} 1-\mathrm{W} 2}{\mathrm{~W} 1} \times 100
$$

Where $W_{1}$ and $W_{2}$ are weight losses in acids without and with the inhibitor respectively

\section{Kinetic of corrosion and thermodynamic activation parameters}

In order to study the effect of temperature on the inhibition efficiencies of thio-urea, the experiment was carried out in the temperature $293 \mathrm{~K} \& 323 \mathrm{~K}$ in the absence and presence of inhibitor at different concentration. The data obtained suggests that thio-urea get adsorbed on the surface of aluminium at all temperature and corrosion rates were increased in the absence and presence on inhibitor with increasing in temperature in $1 \mathrm{M}$ MSA solutions. In acidic media, corrosion of metal is generally accompanied with evolution of $\mathrm{H}_{2}$ gas; rise in temperature usually accelerates the corrosion reactions which results in higher dissolution rate of metal. Two main types of interaction often describe adsorption of organic inhibitors corroding system are physical and chemical adsorption. It has been suggested [2930] that physisorbed molecules are attached to the metal at the cathodes and essentially retard metal dissolution by stifling the cathodic reaction where as chemisorbed molecules protect anodic areas to reduce the inherent reactivity of the metal at the sites where they attacked. The apparent activation energy $\mathrm{E}_{\mathrm{a}}$ for aluminium dissolution in 1 M MSA solution in the absence and presence of inhibitor thio-urea was calculated from Arrhenius equation. [31]

$$
\log \mathrm{r}_{2} / \mathrm{r}_{1} \rightarrow \mathrm{Ea}_{\mathrm{a}} / 2.303 \mathrm{R}\left[1 / \mathrm{T}_{1}-1 / \mathrm{T}_{2}\right]
$$

Where $r_{1}$ and $r_{2}$ are the corrosion rates at temperature $T_{1}$ and $\mathrm{T}_{2}$ respectively

The heat of adsorption ( $Q$ ads) was obtained from the trend of surface coverage with temperature as follows [32].

$$
\begin{aligned}
& \text { Qads } \rightarrow 2.303 \mathrm{R}\left[\log \left(\theta_{2} / 1-\theta_{2}\right)-\log \left(\theta_{1} / 1-\theta_{1}\right)\right] \times\left[\mathrm{T}_{1}\right. \\
& \left.\mathrm{T}_{2} / \mathrm{T}_{2}-\mathrm{T}_{1}\right]
\end{aligned}
$$

Where $\theta_{1}$ and $\theta_{2}$ are degree of surface coverage at temperatures $\mathrm{T}_{1}$ and $\mathrm{T}_{2}, \mathrm{R}$ is the gas constant.

\section{Adsorption isotherm}

Adsorption isotherm is very important in understanding the mechanism of inhibition of corrosion reactions. The most frequently used adsorption isotherms are Frumkin, Temkin, Freundlich, Florry Huggins, Bockris-Swinkel, El-Awardy and Langmuir isotherms. All these isotherms can be represented as follows,

$$
\mathrm{f}(\theta, \mathrm{x}) \exp (-2 \mathrm{a} \theta) \rightarrow \mathrm{kC}
$$

Where $f(\theta, x)$ is the configuration factor which depends upon the physical model and the assumptions underlying the derivation of the isotherm, $\theta$ is the degree of surface coverage, $\mathrm{C}$ is the inhibitor concentration in the electrolyte, $\mathrm{x}$ is the ratio, $\mathrm{a}$ is the molecular interaction parameter and $\mathrm{k}$ is the equilibirium 
constant of the adsorption process. So it is necessary to determine empirically which isotherm fits best to the adsorption of inhibitor on the aluminium surface.

\section{Scanning Electron Microscopy}

A Scanning Electron Microscope is a type of electron microscope that produces images of a sample by scanning it with a focused beam of electrons. The electrons interact with atoms in the sample, producing various signals that can be detected and that contain information about the sample's surface topography and composition. The electron beam is generally scanned in a raster scan pattern, and the beam's position is combined with the detected signal to produce an image.

SEM can achieve resolution better than 1 nanometer. Specimens can be observed in high vacuum, in low vacuum, in wet conditions and at wide range of cryogenic or elevated temperature. The most common mode of detection is by secondary electrons, emitted by atoms excited by the electron beam. On a flat surface, the plume of the secondary electrons is mostly contained by the sample, but on a tilted surface, the plume is partially exposed and more electrons are emitted. By scanning the sample and detecting the secondary electrons, an image displaying the topography of the surface is created.

For SEM analysis the aluminium specimens were immersed for 12 hours in 1M MSA solution under stationary conditions. At the end of treatment the specimens were taken from the solutions, rinsed with deionised water and dried under a stream of nitrogen gas. Surface morphology was inspected and analyzed with a scanning electron microscope.

\section{Results and Discussion}

\section{Weight loss consideration}

The weight losses for aluminium in various concentrations of sulphuric acid and MSA were determined for 3 days at 24 hours intervals. The results obtained are presented in table 1 . It shows that the corrosion rate increases as the concentration of both the acids and the immersion period is increased. From the figure 1, it is clear that MSA is less corrosive than sulphuric acid on the aluminium metal at all concentration.

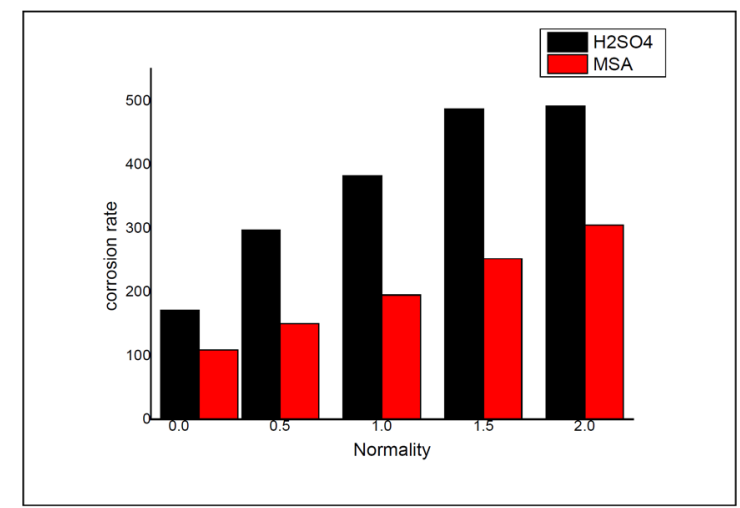

Figure 1: Comparison of variation of corrosion rate with different normality of H2So4 and MSA

\begin{tabular}{|c|c|c|c|c|c|c|}
\hline \multicolumn{7}{|c|}{ Table 1: Corrosion Rate of $\mathrm{Al}$ in $\mathrm{H}_{2} \mathrm{SO}_{4} \&$ MSA. } \\
\hline Normality & \multicolumn{2}{|c|}{$\mathbf{2 4}$ hours } & \multicolumn{2}{|c|}{$\mathbf{4 8}$ hours } & \multicolumn{2}{|c|}{$\mathbf{7 2}$ hours } \\
\hline & $\mathbf{H}_{\mathbf{2}} \mathbf{S O}_{\mathbf{4}}$ & $\mathbf{M S A}$ & $\mathbf{H}_{\mathbf{2}} \mathbf{S O}_{\mathbf{4}}$ & $\mathbf{M S A}$ & $\mathbf{H}_{\mathbf{2}} \mathbf{S O}_{\mathbf{4}}$ & $\mathbf{M S A}$ \\
\hline $0.1 \mathrm{~N}$ & 89 & 28 & 101 & 81 & 171 & 109 \\
\hline $0.5 \mathrm{~N}$ & 93 & 32 & 227 & 122 & 297 & 150 \\
\hline $1.0 \mathrm{~N}$ & 101 & 73 & 260 & 130 & 382 & 195 \\
\hline $1.5 \mathrm{~N}$ & 138 & 77 & 333 & 140 & 487 & 252 \\
\hline $2.0 \mathrm{~N}$ & 142 & 85 & 340 & 158 & 492 & 305 \\
\hline
\end{tabular}

Table 2: Corrosion parameters of aluminium in $1 \mathrm{M}$ MSA in absence and presence of different concentration of thio-urea from weight loss measurements.

\begin{tabular}{|c|c|c|c|}
\hline $\begin{array}{c}\text { Concentration of } \\
\text { thio-urea } \\
\text { (ppm) }\end{array}$ & $\begin{array}{c}\text { Corrosion } \\
\text { rate } \\
\text { (mdd) }\end{array}$ & $\begin{array}{c}\text { Percentage of In- } \\
\text { hibition } \\
\text { Efficiency (I \%) }\end{array}$ & $\begin{array}{c}\text { Degree of } \\
\text { surface } \\
\text { coverage ( } \boldsymbol{\theta})\end{array}$ \\
\hline Blank & 137.09 & - & - \\
\hline 100 & 99.01 & 27.28 & 0.28 \\
\hline 200 & 68.55 & 57.00 & 0.58 \\
\hline 300 & 30.46 & 77.78 & 0.78 \\
\hline 400 & 45.69 & 66.67 & 0.67 \\
\hline
\end{tabular}

Table 3: Inhibition efficiency (I), activation energy (Ea) and heat of adsorption (Qads) for thio-urea on aluminum in 1M MSA at different temperature

\begin{tabular}{|l|l|l|l|l|}
\hline $\begin{array}{l}\text { Concentration of thio- } \\
\text { urea (ppm) }\end{array}$ & \multicolumn{2}{|l|l|}{$\begin{array}{l}\text { Inhibition } \\
\text { efficiency (I \%) }\end{array}$} & $\begin{array}{l}\mathbf{E}_{\mathbf{a}} \mathbf{C} \\
\text { KJmol-1) }\end{array}$ & $\begin{array}{l}\mathbf{Q}_{\text {ads }} \mathbf{C} \\
\text { KJmol-1) }\end{array}$ \\
\cline { 2 - 5 } & at $\mathbf{3 0}^{\circ} \mathbf{C}$ & at $\mathbf{6 0} \mathbf{0}^{\circ} \mathbf{C}$ & & \\
\hline Blank & - & - & 0.275 & - \\
\hline 100 & 25.41 & 18.71 & 0.32 & -0.195 \\
\hline 200 & 48.53 & 33.77 & 0.401 & -0.309 \\
\hline 300 & 76.57 & 59.08 & 0.554 & -0.459 \\
\hline 400 & 72.92 & 54.57 & 0.534 & -0.413 \\
\hline
\end{tabular}

Similarly, it was observed that thiourea inhibits the corrosion of aluminium in 1M MSA solution at all concentration used in study from 100 to $400 \mathrm{ppm}$. Maximum inhibition efficiency was shown at $300 \mathrm{ppm}$ and it reached $78 \%$. It is evident from Table 2, that the corrosion rate is decreased with increasing the concentration of thiourea.

The results suggests that the increase the efficiency with increasing in inhibitor concentrations because of increase the number of molecules adsorbed on the aluminium surface and reduce the surface area that is available for the direct acid attack of the metal surface[33].

\section{Effect of Temperature}

A decrease the inhibition efficiency with rise in temperature with analogous increase in corrosion activation energy in the presence of inhibitor compared to its absence is frequently 
interpreted that the formation of an adsorption film of physical nature. The effect corresponding to an increase in inhibition efficiency with rise in temperature and lower the activation energy in the presence of inhibitor suggest a chemisorptions mechanism. From the foregoing, the trend for the thiourea inhibitor suggests a predominant effect physisorption of inhibiting species on aluminium in 1 M MSA

It is also evident that Qads values are negative ranged from - 0.195 to $-0.413 \mathrm{KJ} \mathrm{mol}$. The negative Qads values show that the physical adsorption and inhibition efficiency decreases with rise in temperature.

\section{Adsorption considerations}

The adsorption of an organic molecule on the aluminium surface is regarded as a substitution reaction between the organic inhibitor in the aqueous phase $\left(\mathrm{I}_{\mathrm{aq}}\right)$ and the water molecules adsorbed on the aluminium surface aluminium surface $\left(\mathrm{H}_{2} \mathrm{Oaq}\right)[34,35]$.

$$
\mathrm{I}_{\mathrm{aq}}+\mathrm{xH}_{2} \mathrm{O}_{\mathrm{ads}} \rightarrow \mathrm{I} \text { ads }+\mathrm{xH}_{2} \mathrm{O}_{\mathrm{aq}}
$$

Where $\mathrm{x}$ is the size ratio of the number of molecules replaced by the adsorbed molecules

However, the adsorption of these organic molecules at the metal/solution interface may take place via four different routes:

1. The electrostatic attraction between charged molecule and the charged metal;

2. Interaction of unshared electron pairs in the molecules with the metal;

3. Interaction of $\pi$-electrons with the metals and

4. Combination (i) - (iii).

Due to adsorption, inhibitor molecules block the active sites and reduce the rate of corrosion reaction by hindering the diffusion of corrosive species or increasing the anodic and cathodic behaviour of the aluminium surface or increasing the resistance of the aluminium surface. Inhibition efficiency depends on several factors, such as number of adsorption sites, inhibitor molecular size and concentration as well as mode of interaction between the aluminium surface and the inhibitor.

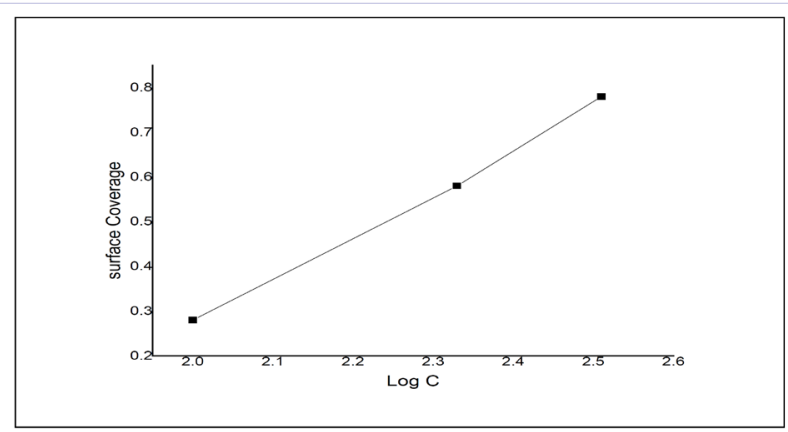

Figure 2: Temkins adsorption isotherm for thio-urea on aluminium in 1 M MSA

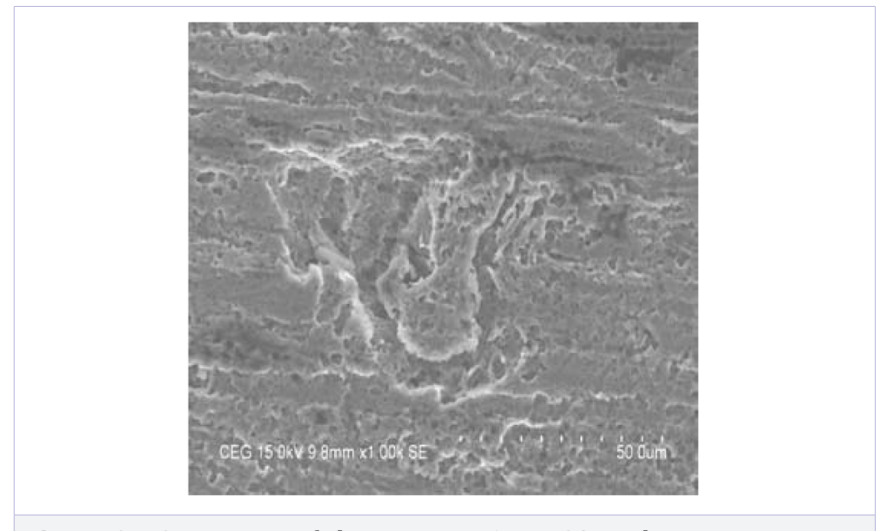

Figure 3a: SEM image of aluminium in 1 M MSA medium

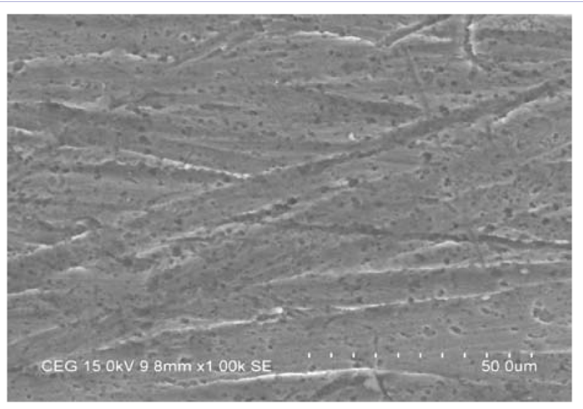

Figure 3b: SEM image of aluminium in 1 M MSA medium in presence of thiourea $(300 \mathrm{ppm})$.

According to the mechanism of inhibition proposed by Bockris and Drazic, the inhibition of an organic inhibitor on the aluminium surface is due to formation of metal-inhibitor complex (Al-Inh) ads on the metal/solution interface.

$$
\mathrm{Al}+\mathrm{Inh} \rightarrow(\mathrm{Al}-\mathrm{Inh}) \text { ads }
$$

When the equilibrium of adsorption is reached, it is then possible to obtain expressions of the adsorption isotherm plots. Adsorption isotherms are very important in understanding the mechanism of organo-electrochemical reactions. The surface coverage $(\theta)$ values were tested graphically by fitting a suitable adsorption isotherm. The plot of $\theta$ versus $\log C$ for different concentration of thio-urea shows a straight line indicating that the adsorption of the compound on the composite surface follow Tomkins adsorption isotherm.

The applicability of Temkins adsorption isotherm verifies the assumption of monolayer adsorption on the uniform homogeneous surface of aluminium with an interaction in the adsorption layer.

\section{Analysis of surface metal scanning electron microscope}

SEM technique provides a pictorial representation of the surface. To understand the nature of the surface film in the presence and absence of inhibitors and the extent of corrosion products of aluminium, the SEM micrographs of the surface are examined [36,37]. The image Fig.3 (a) denote the SEM micrographs of aluminium surface immersed in MSA indicate 
the surface is highly corroded. The image Fig 3(b) confirms that in the presence of $300 \mathrm{ppm}$ of thio-urea, the rate of corrosion is suppressed, as it seen from the decrease in corroded areas.

This is a result shows that the surface is covered by a thin layer of inhibitors which effectively controls the dissolution of aluminium metal from corrosion products. The above results are line with the interpretation made by $[39,40]$

\section{Conclusion}

The following conclusions can be drawn from the investigation.

1. The corrosion rate of aluminium in Methane Sulphonic Acid is lesser than Sulphuric acid.

2. Thiourea showed good corrosion inhibition properties against corrosion in the MSA media.

3. The inhibition efficiency decreased with increasing temperature as a result of higher desorption of the inhibitor from the aluminium surface and the efficiency increased when the concentration increased for all temperatures.

4. Adsorption of this inhibitor on the aluminium surface can be closely modeled to the Temkins adsorption isotherm.

5. The negative values of $Q$ ads shows that the inhibition efficiency decreases with increase in temperature

6. Thermodynamic data suggests physical adsorption for the inhibitor on aluminium surface.

7. The scanning electron microscope (SEM) images show the retarding of aluminium corrosion in acid solution by this inhibitor.

\section{References}

1. B Sanyat. Corrosion inhibition of mild steel in $1 \mathrm{M} \mathrm{HCl}$ solution by Xylopia ferruginea leaves. Journal of chemical Act. 1981;9:165-236.

2. EE Oguize, VO Njoku, CK Enenebeaku, CO Akalezi, C Obi. Effect of hexamethyl pararosaniline chloride (crystal violet) on mild steel corrosion in acidic media. Adsorption Sci Technol. 2008;18:177. doi. org/10.1016/j.

3. M Kissi; M Bouklah; B Hammouti, N Benkaddour. Establishment of equivalent circuits from electrochemical impedance spectroscopy study of corrosion inhibition of steel by pyrazine in sulphuric acidic solution. Appl surf sci. 2006;252(12): 4190-4197. doi. org $/ 10.1016 / \mathrm{j}$.

4. R Rosliza, WB Wan Nik, H.B.senin. The effect of inhibitor on the corrosion of aluminium alloy in acidic solutions. 2008;107(23):281-288. doi.org/10.1016/j.

5. M Gopiraman, C Sathya, S Vivekananthan, D Kesavan, N Sulochana. Influence of 2, 3-Dihydroxyflavanone on Corrosion Inhibition of Mild Steel in Acidic Medium. 2012;21(2):240-246. DOI: 10.1007/ s11665-011-9925-0

6. L Tang, Xli, G Mum, G Liu, I Li, H Liu, Y Si J. The synergistic inhibition between hexadecyl trimethyl ammonium bromide (HTAB) and $\mathrm{NaBr}$ for the corrosion of cold rolled steel in 0.5 M sulfuric acid. Master Sci . 2006;41(10):3063-3069. DOI: 10.1007/s10853-006-6987-8
7. SA Umoren, MM solomon. Effect of halide ions on the corrosion inhibition of organic species - A Review. Electro chem. 2015;21:81100. doi.org $/ 10.1016 / \mathrm{j}$.

8. D Zhang, L Gao, G Zhou. Inhibition of copper corrosion in aerated Hydrochlororic acid. J Appl Electro chem. 2005;35(11):1081-1085. DOI: $10.1007 / \mathrm{s} 10800-005-9009-7$

9. L Nnanna, I Anozie, A Avoaja, C Akoma, E Eti Afr. The effect of inhibitor on the corrosion of aluminium alloy in acidic solutions. Journal. Of Pure and Applied Chem. 2014;4(4):178-183. doi:10.5923/j.materials.20140404.04

10. Y Harek, L Larabi, Kem. Adsorption and Corrosion Inhibition of Atropa Belladonna Extract on Carbon Steel in $1 \mathrm{M} \mathrm{HCl} \mathrm{Solution.}$

11. G Gunasekaran, LR Chauhan. "Ecofriendly inhibitor for corrosion inhibition of mild steel in Phosphoric acid medium. 2004;49(25):4387-4395. doi.org/10.1016/j.

12. MD Gernon, MWu, T B u szta, P Janney, "Environmental benefits of methane sulphonic acid. Comparative properties and advantages. Green chem. 1999;1(3):127-140. DOI: 10.1039/A900157C13

13. Matjaz Finsgar, Ingrid Milosev. "Corrosion behavior of stainless steel in aqueous solutions of Methane Sulphonic acid". Corr Science. 2010;52(7):2430-2438. doi.org/10.1016/j.

14. Guthrie JP. "Hydrolysis of esters of oxyacids, PKa values for strong acid". J Chem. 1978;56(17):2342-2357.

15. NM Martyak, P Ricou. "Seed layer corrosion of damascene structures in copper sulfonate electrolytes." Mater Chem Phys. 2004;84 (1):87 - 98. Doi: http://dx.doi.org/10.1016/j.matchemphys.2003.10.008

16. BX Luong, AL Petre WF Hoelderich, A Commarieu, JA Laffitte, M Espeillac, et al. Use of methane sulfonic acid as catalyst for the production of linear alkylbenzenes. J Catal. 2004;226(2):301-307. doi:10.1016/j.jcat.2004.05.025

17. HH Uhlig. Corrosion and Corrosion control, 1964, 40 Corrosion and corrosion control: and introduction to corrosion science and engineering.

18. Anees A Khadom, Aprael S Yaro, Abdul AH Kadum, Ahmed S, AlTaie and Ahmed Y Musa. The Effect of Temperature and Acid Concentration on Corrosion of Low carbon Steel in Hydrochloric Acid media. 2009;6(7):1403-1409. DOI : 10.3844/ajassp.2009.1403.1409

19. MA Quraishi, Jamal d Dianils. New and Effective Corrosion Inhibitors for Oil-Well Steel (N-80) and Mild Steel in Boiling Hydrochloric Acid Corrosion. 2000;56(2):156-160.

20. M Lagrene'e, B Memaru, N Chaibi, M Traisnel, H Vezin, F Bentiss. Corrosion Inhibition of copper in Nitric Acid Solutions Using a New Trizole Derivative. Corros Sci. 2001;43(5):951-962.

21. SS Abd EI-Rehim, M Ibrahim, KF Khaled. The inhibition of 4-(2'-amino-5'-methylphenylazo $)$ antipyrine on corrosion of mild steel in $\mathrm{HCl}$ solution. Materials Chemistry and Physics. 2001;70(3):268-273. Doi:10.1016/S0254-0584(00)00462-4.

22. F Bentiss, M Traisnel, L Gengembre, M Lagrene'e. Electrochemical and XPS studies of 2,5-bis(n-pyridyl)-1,3,4-thiadiazoles adsorption on mild steel in perchloric acid solution. Appl Surf Sci. 2002;152(3-4):237-249. Doi: http://dx.doi.org/10.1016/S01694332(01)00650-X

23. MG Mertons, M Ghorbani, MR Arshadi, Corrosion inhibition of mild steel by two new S-heterocyclic compounds in $1 \mathrm{M} \mathrm{HCl}$ : Experimental 
and computational study Master Chem Phys. 2003;78(3):800-808.

24. M. Migahed, HM Mohamed, AM Al-Sabagh. Structure effect of some amine derivatives on corrosion inhibition efficiency for carbon steel in acidic media using electrochemical and Quantum Theory. Master Chem Phys. 2013;22(1):101-116. DOI: http://dx.doi.org/10.1016/j. ejpe.2012.09.004

25. E Khamis, El Ashry, AB Ibrahim. Synergistic action of vinyl triphenyl phosphonium bromide with various anions on corrosion of steel. Br Corros Journal. 2000;35(2):150-154. doi:10.1179/000705900101501191.

26. A Popova, E Sokolava, S Raicheva, M Chritov. Inhibition of Mild Steel Corrosion by Aspilia Africana in $1 \mathrm{M} \mathrm{H}_{2} \mathrm{SO}_{4}$. Corros sci. 2003;45(1):33-58.

27. MEl Azhar, B Memari, M Trisnel, F Bentiss, M Lagrene'e. Corros Sci., 2001;43(12):2229-2238.

28. L Afia, N Rezhi, A Zarrouk, H Zarrouk, R Salghi, B Hammouti, $\mathrm{M}$ Messali, SS Al Deyab. Corrosion Inhibition of Steel in $\mathrm{HCl}$ by 2-Aminoethyl diphenylborinate. Int J Electro Chem Sci. 2014;9:54795495

29. E Ebenso, PC Okafur, Ekpe, UJ Bull. Corrosion Inhibition of mold steel in acidic media by some organic dyes. 2005;59(17):2163-2165. DOI: http://dx.doi.org/10.1016/j.matlet.2005.02.055

30. U Ekpe, E Ebenso, B Antia. Corrosion Inhibition of Aluminium using exudates gum from Pachylobus edulis in the Presence of Halide ions in HCl. West Afri J Boil Appl Chem. 2008;5(2):355-364. DOI: http:// dx.doi.org/10.1155/2008/138407

31. MA Quraishi, D Jamal. Inhibition of mild steel corrosion in the presence of fatty acid triazoles. Corros Sci. 2002;32(4):425430. DOI: 10.1023/A:1016348710085

32. Bothiraja, Mathur GopalakrishnanSethuraman. Solanum Tuberosum as an Inhibitor of Mild Steel Corrosion in Acid Media. Iran J Chem Engg. 2009;28(1):77-82.
33. E. Oguzie. Corrosion inhibitive effect and adsorption behavior of Hibiscus sabdariff extract on mild steel in acidic media. Portugalete Electro chem Acta. 2008;26:303-314.

34. Okafor PC, Ebenso EE, Ekpe U Azadirachta indica extracts as corrosion inhibitor for mild steel in acid medium. International Journal of Electrochemical Science. 2010,5:978-993.

35. Obot IB. Synergistic effect of Nizoral and Iodide ions on the corrosion inhibition of mild steel in sulphuric acid solution. Portugaliae. Electro chemical Acta. 2009;27(5):539-553. DOI: 10.4152/pea.200905539.

36. Herbert D Johansen, Christopher M A Brett, Artur J Motheo. Corrosion protection of aluminium alloy, by cerium conversion and conducting polymer duplex coatings. Corros Sci. 2012;63:342-350. doi:10.1016/j.corsci.2012.06.020.

37. Matarredona O M, Mack K, Rieger M M, O' Rear E A. Alteration of wettability and inhibition of corrosion in narrow aluminium 7075 gaps by thin polymer films. Corros Sci. 2003;45(11):2541-2562. doi:10.1016/S0010-938X(03)00084-2.

38. Ganesha Achary Y, Arthoba Naik, Vijay Kumar S, VenkateshaTV, Sherigara BS. An electro active Copolymer as corrosion inhibitor for steel in sulphuric acid medium. Appl Surf Sci. 2008;254(17):55695573. doi:10.1016/j.apsusc.2008.02.103.

39. Feng Y, Siow KS, Teo WK, Tan KL, AK, Hsieh AK. Synergistic effects between Sodium Tripolyphosphate and Zinc sulphate in corrosion inhibition for copper in Neutral Tap water. Corros sci. 1997;53(7):546-555. doi:http://dx.doi.org/10.5006/1.3290286.

40. Weihua Li, Lichao Hu, Shengtao Zhang and Baorong Hou. Effects of two fungicides on the corrosion resistance of copper in $3.5 \% \mathrm{NaCl}$ solution under various conditions. Corr Sci. 2011;53(2):735-745: doi:10.1016/j.corsci.2010.11.006. 